\title{
The effect of particles on dynamic recrystallization and fabric development of granular ice during creep
}

\author{
Min SONG, ${ }^{1}$ Ian BAKER, ${ }^{1}$ David M. COLE ${ }^{2}$ \\ ${ }^{1}$ Thayer School of Engineering, Dartmouth College, Hanover, New Hampshire 03755-8000, USA \\ E-mail: ian.baker@dartmouth.edu \\ ${ }^{2}$ US Army Cold Regions Research and Engineering Laboratory, 72 Lyme Road, Hanover, New Hampshire 03755-1290, USA
}

\begin{abstract}
The mechanical behavior and microstructural evolution of laboratory-prepared, particlefree fresh-water ice and ice with $1 \mathrm{wt} . \%(\sim 0.43 \mathrm{vol} . \%)$ silt-sized particles were investigated under creep with a stress level of $1.45 \mathrm{MPa}$ at $-10^{\circ} \mathrm{C}$. The particles were present both within the grains and along the grain boundaries. The creep rates of specimens with particles were always higher than those of particlefree ice. Dynamic recrystallization occurred for both sets of specimens, with new grains nucleating along grain boundaries in the early stages of creep. The ice with particles showed a higher nucleation rate. This resulted in a smaller average grain-size for the ice with particles after a given creep strain. Fabric studies indicated that ice with particles showed a more random orientation of $c$ axes after creep to $\sim 10 \%$ strain than the particle-free ice.
\end{abstract}

\section{INTRODUCTION}

The effects of dispersed particles on the creep behavior of polycrystalline ice have been investigated by a number of workers (Holdsworth and Bull, 1970; Nayar and others, 1971; Baker and Gerberich, 1979; Lange and Ahrens, 1983; Shoji and Langway, 1985; Durham and others, 1992; Song and others, 2004). These studies include ice containing ultrafine (15 nm diameter) amorphous silica particles (Nayar and others, 1971; Lange and Ahrens, 1983), which show similar mechanical behavior to particle-strengthened metals, i.e. at low concentrations the strength increases as the particle content increases. In contrast, when the particle size is similar to that of silt (several hundred microns), the particles can decrease the strength (Holdsworth and Bull, 1970; Baker and Gerberich, 1979; Shoji and Langway, 1985). For example, Baker and Gerberich (1979) found that at temperatures from $-20^{\circ} \mathrm{C}$ to $-5^{\circ} \mathrm{C}$, solid inclusions in concentrations from 1.3 to 6.6 vol.\%, increased the creep strain rate; Shoji and Langway (1985) found an increased flow rate for dirty basal ice from Camp Century, Greenland, compared with clean basal ice; Holdsworth and Bull (1970) observed an enhanced flow rate in the basal amber-colored ice of Meserve Glacier, Antarctica; Song and others (2004) observed an increased flow rate for laboratory-grown granular ice containing $0.1-4$ wt. $\%$ particles distributed along the grain boundaries.

Microstructural evolution will strongly affect the deformation process: both the grain-size and the orientations of the grains will affect the deformation rates and mechanisms. Decreasing the grain-size can change the creep mechanism from dislocation glide to a diffusion-based grain boundary sliding mechanism (Goldsby and Kohlstedt, 1997). Jacka and Maccagnan (1984) indicated that the creep rate can increase by up to a factor of three times the minimum creep rate, and grains show a weak girdle-shaped $c$-axis orientation after $7.3 \%$ strain in uniaxial compression tests. Cuffey and others $(2000 a, b)$ found an enhanced shear strain rate of ice-age ice in southern Greenland; they suggested that this arose from the development of $c$-axis fabric with a strong shear single maximum pattern and decrease in grain-size, with these two phenomena accounting for roughly $70 \%$ and $30 \%$ of the average enhancement. Thus, studying microstructural evolution is important to fully understand creep processes.

There are a number of studies (Duval, 1981; Jacka, 1984a; Jacka and Maccagnan, 1984; Azuma and Higashi, 1985; Wilson and Sim, 2002) concerning fabric development in laboratory-prepared and glacier ice. These studies examined fabric development under compression and shear. The studies indicate that a girdle-shaped polar figure will be formed during low-stress symmetric or nearly symmetric uniaxial compression. Generally, these small girdle-shaped circles are seen when the strain is above $10 \%$. However, Jacka and Maccagnan (1984) showed that a girdle-shaped circle can be generated even when the strain is as low as $7.3 \%$. Although the stresses $(0.1-0.6 \mathrm{MPa})$ used in the above fabric studies are higher than those observed in almost all natural ice, they might still not be high enough to affect the recrystallization mechanisms. However, compared with fabric development at those stress levels, fabric development under even higher stress may be different because the internal stress generated along the grain boundaries and particles during creep may not have enough time to be released (at high deformation rates). Van der Veen and Whillans (1994) developed a simulation for fabric development at a stress of $0.2 \mathrm{MPa}$ and assumed that dynamic recrystallization occurred via strain-induced grain boundary migration (SIBM). They found that the simulation only worked well for short times when the lattice rotations were small. However, under high stress, recrystallization may not occur by SIBM but through the nucleation and growth of many small grains along the grain boundaries (Humphreys and Hatherly, 1996). This is due to the high strain energy that is built up along the grain boundaries under high stresses. This process will inevitably increase the number of grains. Furthermore, because strain energy can build up around the particles during deformation, the particles can stimulate the nucleation of new grains. Since the particles are distributed both along the grain boundaries and in the grain interiors, these new grains appear throughout the specimen, not just along the grain boundaries. Studies on metals and alloys (Habiby and Humphreys, 1999; Huang and Humphreys, 


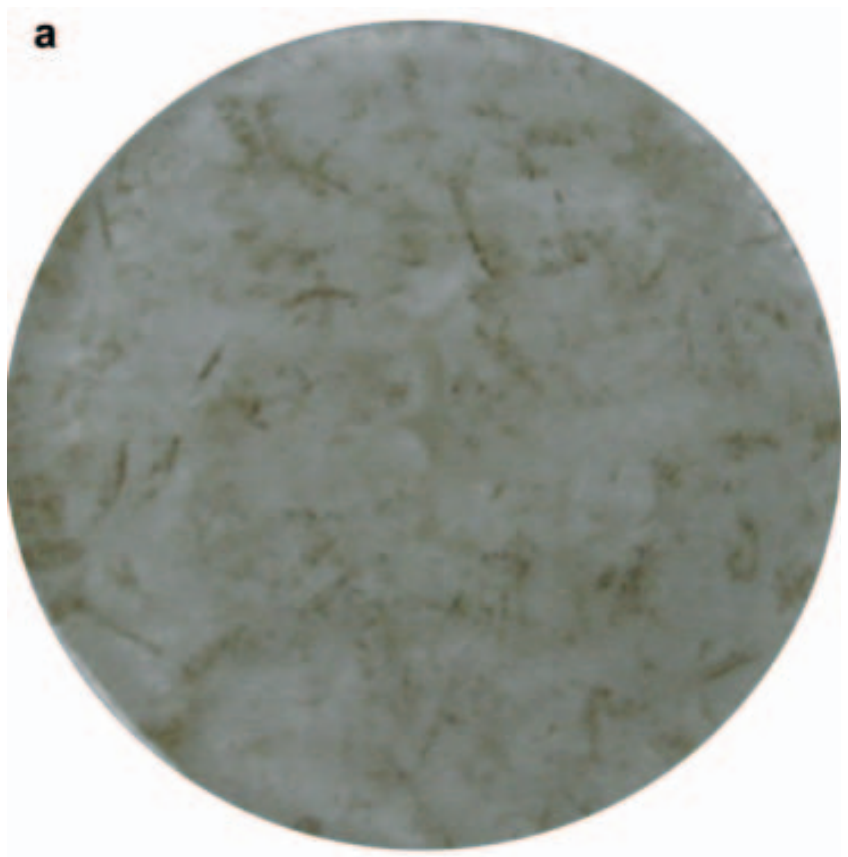

$50.4 \mathrm{~mm}$

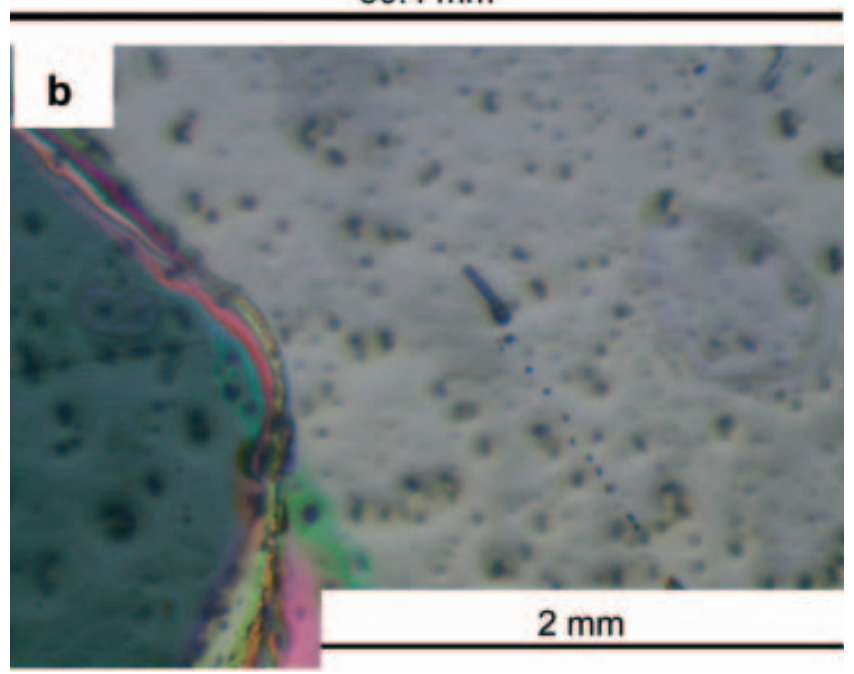

Fig. 1. (a) Photograph of a thin section of an ice specimen with $1 \mathrm{wt} \% \%$ particles. (b) Enlarged view of the thin section under polarized light showing the distribution of particles.

1999; Somerday and Humphreys, 2003) show that large second-phase particles enhance dynamic recrystallization during deformation by acting as preferred sites for nucleation; this is called particle-stimulated nucleation (PSN). In some previous PSN studies, Bleck and Bunge (1981) found a nearly random orientation distribution in fully recrystallized grains in an $\mathrm{Al}-\mathrm{Mn}$ alloy, while Habiby and Humphreys (1999) showed that in an Al-Si alloy most of the recrystallized nuclei forming around the particles are misoriented from the adjacent deformed matrix by $30-45^{\circ}$.

Our research is motivated by the need to understand how fine particles affect the mechanical behavior of ice. Since the flow processes are inevitably connected with microstructural evolution, the present paper focuses on the effect of dispersed particles, located both in grain boundaries and inside grains, on the creep, dynamic recrystallization and fabric development in laboratory-prepared granular ice specimens.

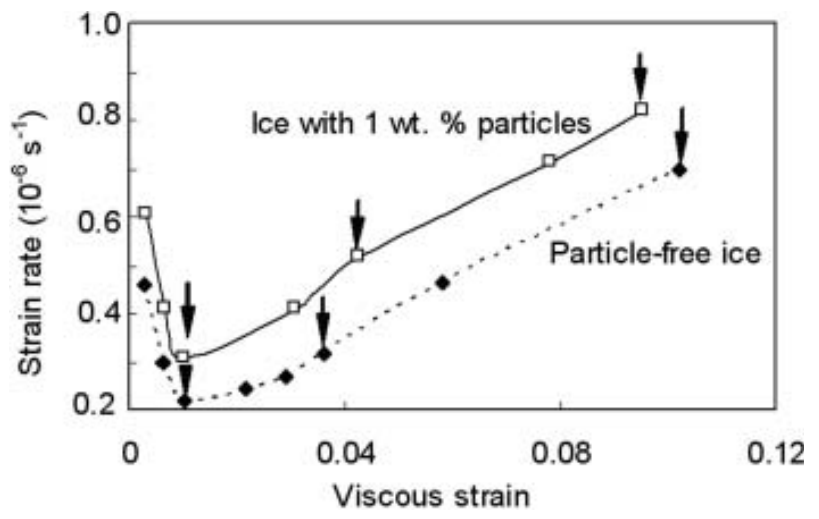

Fig. 2. Relationship between strain rate and viscous strain of particle-free ice and ice with $1 \mathrm{wt} \%$ particles (initial stress level: 1.45 MPa). Arrows indicate the viscous strains used for studying microstructural evolution and fabric development.

\section{EXPERIMENTAL}

Deionized, distilled and degassed water was used to grow thin plates of large-grained ice. These ice plates were then broken up, and the grains were used to seed granular freshwater ice specimens. The final cylindrical specimen dimensions were $127 \mathrm{~mm}$ in length and $50.4 \mathrm{~mm}$ in diameter.

For ice specimens with particles, water with silt-sized soil particles (obtained from Hanover, $\mathrm{NH}$, and sieved to $50 \pm 10 \mu \mathrm{m})$ was frozen to a thickness of about $5 \mathrm{~mm}$ from bottom to top using a cooling plate. Another layer of ice with particles was then grown on the top of the first layer. This procedure was repeated several times until the thickness of the ice plate was about $30 \mathrm{~mm}$. (It was necessary to grow a multilayer ice plate to distribute the particles throughout the ice grains.) The ice plate was subsequently broken up, and a $3-5 \mathrm{~mm}$ sieve fraction was obtained. These grains were then used to seed granular fresh-water ice specimens prepared by the method of Cole (1979). Both the particle-free ice and the ice with particles had an average initial grain-size of approximately $5 \mathrm{~mm}$. Figure 1 shows a thin section and an enlarged view of ice with 1 wt. \% ( 0.43 vol.\%) particles. It can be seen that the particles are uniformly distributed (Fig. 1b). Unlike a previous study (Song and others, 2004), in which the particles were located only along the grain boundaries, here the particles are distributed both along the grain boundaries and inside the grain interior.

Constant-load creep tests with an initial stress level of 1.45 $\mathrm{MPa}$ at $-10^{\circ} \mathrm{C}$ were used to study the effect of particles on the creep behavior. After the creep strain reached $~ 10 \%$, the stress had decreased to $\sim 1.3 \mathrm{MPa}$, i.e. about $10 \%$ lower than the initial stress, due to the increase in the specimen's cross-sectional area. A load cell mounted in line with the specimens monitored the axial load, and two displacement transducers mounted on circumferential rings (located at one-third and two-thirds along the length of the specimens) provided the deformation measurements.

The experiments employ cyclic loading to determine the dislocation density based on a dislocation-drag model (Cole, 1995; Cole and Durell, 2001). During cyclic tests, a zeromean-stress sinusoidal waveform was applied to the specimens by an electro-hydraulic actuator. The experiments employed the reversed direct-stress testing method developed by Cole and Durell (1995), and the procedures 


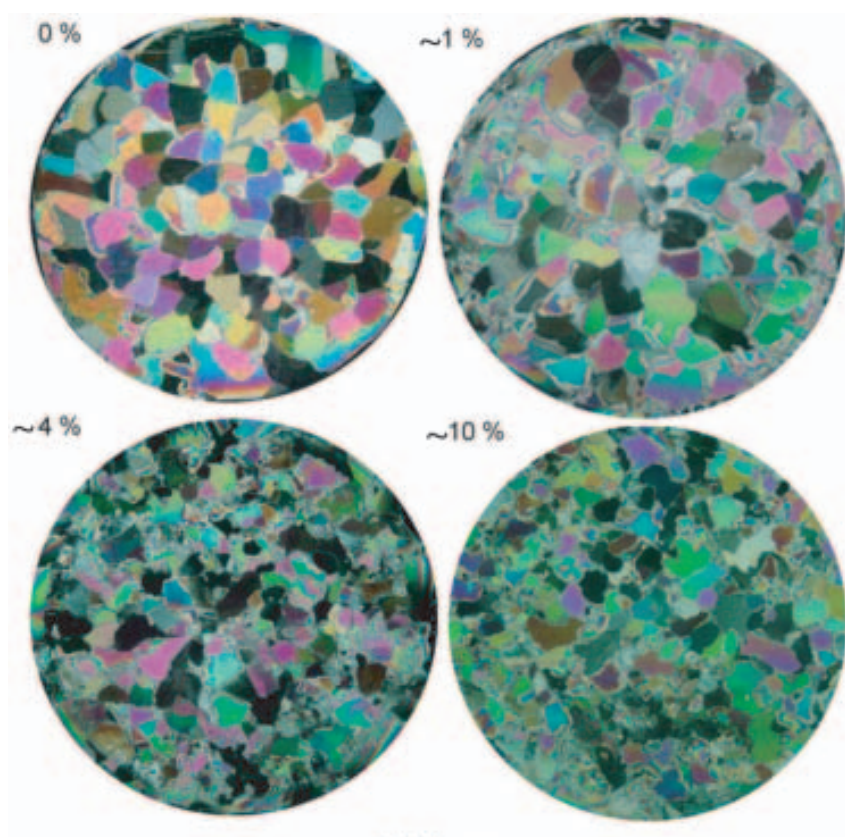

$50.4 \mathrm{~mm}$

Fig. 3. Thin sections of particle-free ice under polarized light at the indicated levels of creep viscous strain.

described by Cole (1993). These tests also show the grain boundary relaxation peak that occurs at high frequencies. Thus, to study the effects of particles on the grain boundary sliding, cyclic loading was applied to the specimens to determine the internal friction. The internal friction (the ratio of the hysteresis loop area to the peak strain energy during a load cycle) is a dimensionless measure of the energy dissipated per cycle.

After creep (strains of $\sim 1-10 \%$ ) the specimens were thinsectioned in order to study the effects of particles on both dynamic recrystallization and fabric development. Microstructural analysis was performed using optical microscopy with polarized light. Fabric studies used the method developed by Langway (1958) to determine the $c$-axis orientation to $\pm 5^{\circ}$. The orientation of each specimen was measured by two workers (Song and E. Andreas) to ensure the accuracy of the fabric studies.

\section{RESULTS AND DISCUSSION \\ Creep}

Figure 2 shows the relationship between strain rate and viscous strain for both the particle-free ice and the ice with $1 \mathrm{wt} . \%$ particles. It should be noted that the viscous strain does not include the elastic and anelastic components, which have been removed from the total strain because these two components will not affect the microstructure. Note that the creep rate of the ice with particles was always higher than that of the particle-free specimens, even at strains that are too low for appreciable recrystallization to occur. This agrees well with a previous study (Song and others, 2004), in which particles are distributed only along the grain boundaries and also show increased creep rates, compared with those of particle-free ice. The higher creep rate of ice with particles is possibly due to an increased dislocation density caused by the particles. Since under these conditions $\left(-10^{\circ} \mathrm{C}\right.$ and $\left.1.45 \mathrm{MPa}\right)$ the main creep

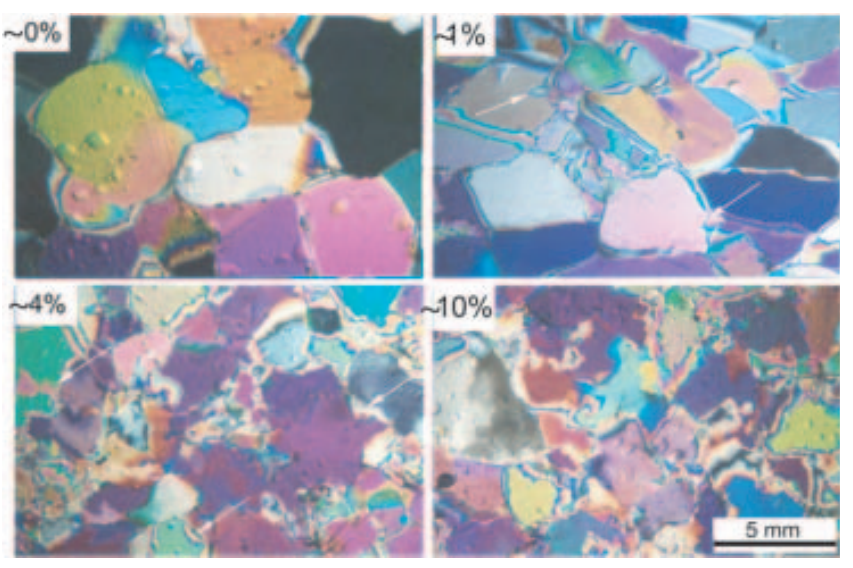

Fig. 4. Enlarged microstructural views of particle-free ice at the indicated levels of creep viscous strain.

mechanism is dislocation glide on the basal plane (Duval and others, 1983), an increase in dislocation density will inevitably increase the creep rate. The curves in Figure 2 show typical creep behavior: the creep rate initially decreases (primary creep) to a minimum value and then increases (tertiary creep). During tertiary creep, dynamic recrystallization leads to increases in the creep rate. It can be seen that the strain at the minimum creep rate is about 0.01 for both particle-free ice and ice with particles, in agreement with Jacka's data (1984b).

\section{Microstructural evolution}

Figure 3 shows thin sections of the particle-free ice observed using polarized light before and after creep to the indicated strains. Note the refinement, i.e. reduction, in grain-size with increasing strain. Figure 4 shows highermagnification images, where it is evident that dynamic recrystallization has occurred along the grain boundaries (see arrows). In the early stages of creep (strain $\sim 1 \%$ ), few new grains nucleate. With increasing strain, the effect of dynamic recrystallization increases until $\sim 10 \%$ strain, at which point the specimen is substantially recrystallized. New grains replace the initial microstructure, resulting in a decrease in the average grain-size from $\sim 5 \mathrm{~mm}$ to $\sim 2 \mathrm{~mm}$ after $10 \%$ strain.

Figure 5 shows the thin sections of ice with $1 \mathrm{wt} \%$ particles observed using polarized light both before and after creep to the indicated strains. Again, the grain-size decreases with increasing strain, but more rapidly than in the particle-free ice. Note also the heterogeneity of the microstructure, with some large, probably original, grains in a largely recrystallized matrix. Figure 6 shows enlarged images of the microstructure. Similar to the particle-free ice, new grains nucleate along the grain boundaries, but at a higher nucleation rate (cf. Figs $3-6$ ). Even after only $\sim 1 \%$ strain, the extent of dynamic recrystallization is very high in the ice with particles, with many new grains nucleated along the grain boundaries (see arrows in Fig. 6). At $\sim 10 \%$ strain, the whole microstructure has largely recrystallized, and almost all of the old grains are replaced by the new, small, recrystallized grains. This particle-induced dynamic recrystallization was also observed in a previous study (Song and others, 2004), which focused on the effect of particles on creep in microstructures with particles distributed only along the grain boundaries. 


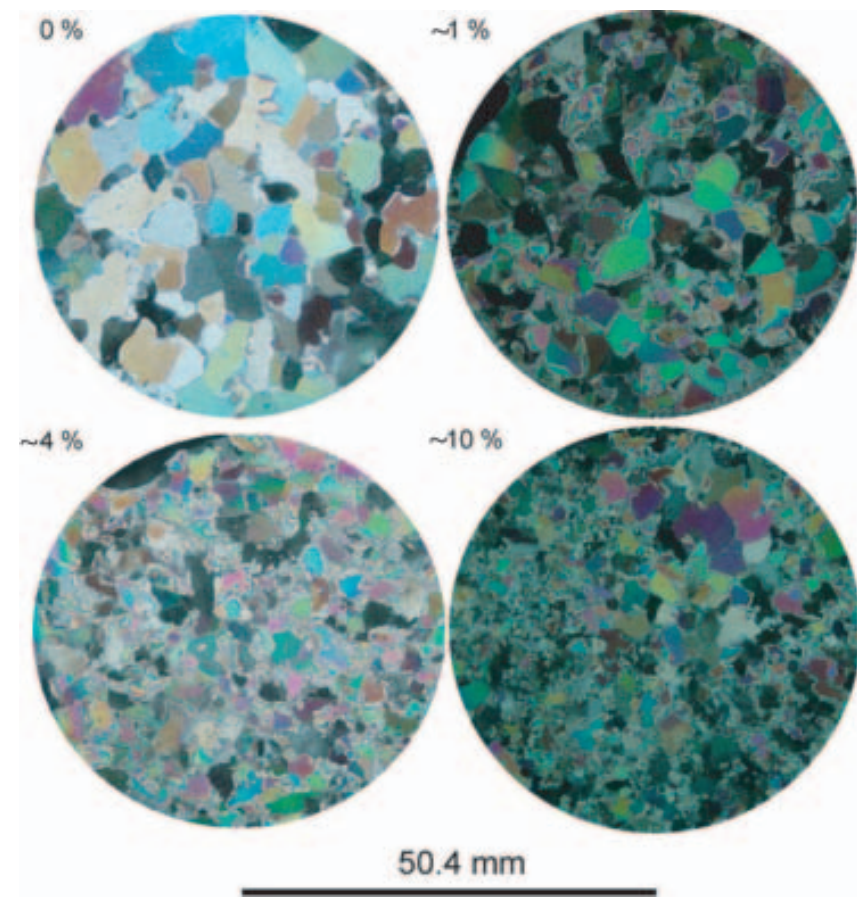

Fig. 5. Thin sections of ice with $1 \mathrm{wt} . \%$ particles at the indicated levels of creep viscous strain.

The particles (both located along the grain boundaries and inside the grain interiors) produce greater strain energy due to local lattice rotations (Humphreys, 1980) than occurs in the particle-free ice, and thus will increase the nucleation rate. This produces a higher recrystallization rate and leads to a greater reduction in grain-size with increasing strain than in the particle-free ice. Table 1 shows the relationship between average grain-size and strain level for particle-free ice, ice with $1 \mathrm{wt} . \%$ particles distributed both along the grain boundaries and in the grain interior, and ice with $1 \mathrm{wt} . \%$ particles distributed only along the grain boundaries for comparison. It can be seen that as the strain increases, the average grainsize decreases, with the ice with particles showing a much larger grain-size reduction than the particle-free ice. Ice with 1 wt.\% particles distributed both along the grain boundaries and in the grain interiors, and ice with $1 \mathrm{wt} . \%$ particles distributed only along the grain boundaries show similar grain-size reduction, indicating that the particles in the grain interiors may have effects on dynamic recrystallization similar to those of the particles along the grain boundaries.
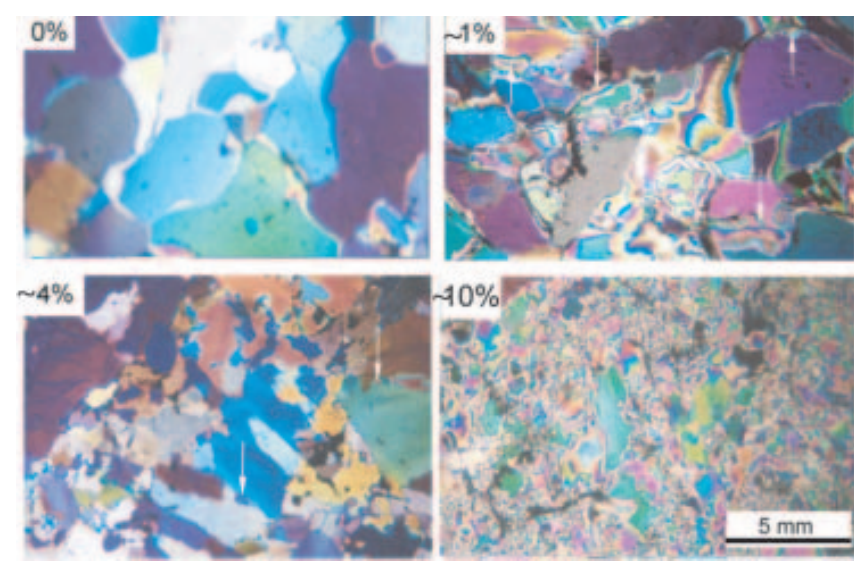

Fig. 6. Enlarged microstructural views of ice with $1 \mathrm{wt} . \%$ particles at the indicated levels of creep viscous strain.

Typically, pure polycrystalline ice exhibits an internal friction peak (Cole, 1995) due to grain boundary sliding located at $\sim 5 \mathrm{~Hz}$ at $-10^{\circ} \mathrm{C}$. Figure 7 shows how particles affect the internal friction before creep. It is evident that the internal friction of the ice with particles is similar to that of particle-free ice at frequencies less than $0.1 \mathrm{~Hz}$, but it is at least $30 \%$ lower at $1 \mathrm{~Hz}$. This result is in accordance with a previous study (Song and others, 2004), which focused on the effect of particles that are located only along the grain boundaries (also see Fig. 7). When particles are uniformly distributed throughout the microstructure, some fraction of them will be located along the grain boundaries. The decrease in internal friction at $1 \mathrm{~Hz}$ for ice with particles indicates that there were a sufficient number of particles along the grain boundaries to block grain boundary sliding and thus eliminate the grain boundary relaxation peak. Baker and others (2000) showed that for polycrystalline fresh-water ice, dislocation nucleation always occurs at the grain boundaries in response to the stresses built up by grain boundary sliding. When particles inhibit grain boundary sliding, the strain energy will increase along the grain boundaries, making them favorable sites for the nucleation of new grains.

\section{Fabric development}

Figure 8 shows the $c$-axis orientations for particle-free ice before and after creep to the indicated strains. It is evident that the random distribution of $c$-axis orientations before

Table 1. The relationship between average grain-size and strain for both particle-free ice and ice with particles

Strain

Particle-free ice $\left(-10^{\circ} \mathrm{C}\right)$
Average grain-size

Ice with 1 wt.\% particles

Both along the grain boundaries and in the grain interiors $\left(-10^{\circ} \mathrm{C}\right)$

$\mathrm{mm}$

Only along the grain boundaries $\left(-12^{\circ} \mathrm{C}\right)$

\begin{tabular}{lcccc}
\hline 0 & 5 & 5 & 5 \\
$\sim 1$ & 4 & 2 & 2.2 \\
$\sim 4$ & 3 & 1 & - \\
$\sim 7$ & - & - & 0.5 \\
$\sim 10$ & 2.2 & 0.2 & - \\
\hline
\end{tabular}




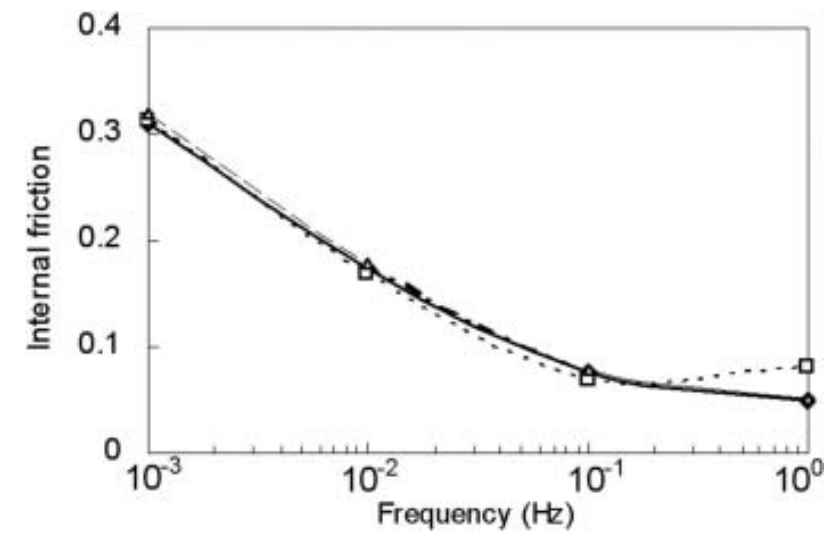

Fig. 7. Relationship between internal friction and frequency for particle-free ice and ice with $1 \mathrm{wt} . \%$ particles (note the difference in behavior at $1 \mathrm{~Hz})$. Short-dashed line: particle-free ice $\left(-10^{\circ} \mathrm{C}\right)$; solid line: ice with $1 \mathrm{wt} . \%$ particles distributed both along the grain boundaries and in the grain interiors $\left(-10^{\circ} \mathrm{C}\right)$; long-dashed line: ice with $1 \mathrm{wt} . \%$ particles distributed only along the grain boundaries $\left(-12^{\circ} \mathrm{C}\right)$.

creep slowly changes to a weak, small girdle-shaped circle when the strain reaches $10 \%$. Actually, during the compressive creep tests, the slip direction rotates away from the compression axis if one considers each crystal individually. Compared with some previous data, which show a strong girdle-shaped orientation at strains above 15\% (Duval, 1981; Azuma and Higashi, 1985), the $~ 10 \%$ strain is rather small to generate such a girdle-shaped fabric in our tests. The reason for this phenomenon is not clear at this stage. However, since our tests use a high stress level, the strain energy developed is also very high, which might help form the girdle-shaped orientation at a lower strain. Jacka and Maccagnan (1984) also show that a girdle shape can form even with only $7.3 \%$ strain during uniaxial compression tests with a stress level of $0.2 \mathrm{MPa}$.

Figure 9 shows the $c$-axis orientations for ice with 1 wt. $\%$ particles before and after creep to the indicated strains. It can be seen that the grains show random orientation at all strain levels, and the fabric after $\sim 10 \%$ strain is much weaker than that for particle-free ice with $\sim 10 \%$ strain. Since the microstructure (Figs 5 and 6 ) shows that almost all the deformed grains were replaced by the new, recrystallized, small grains, the random orientation at $\sim 10 \%$ strain indicates that the new grains do not have preferred orientations. The rather random $c$-axis orientations for ice with particles also suggests that dynamic recrystallization occurs through nucleation of new grains rather than through strain-induced boundary migration (Gottstein and Shvindlerman, 1999) or through polygonization by edge dislocation movement, because the latter two processes will only change the orientation of grains by a few degrees. Thus, if dynamic recrystallization occurs through either of those two processes, a weak small-circle girdle, as found for deformed particle-free ice, should be observed.

Previous studies (Gow and Williamson, 1971, 1976) indicated the existence of dust bands at 1200-1800 m depth in the Byrd (Antarctica) ice cores. These debris bands are estimated to have been deposited in the ice sheet 43500 7500 years ago and consist of volcanic ash. Gow and Williamson (1971) observed that the grain-size decreases

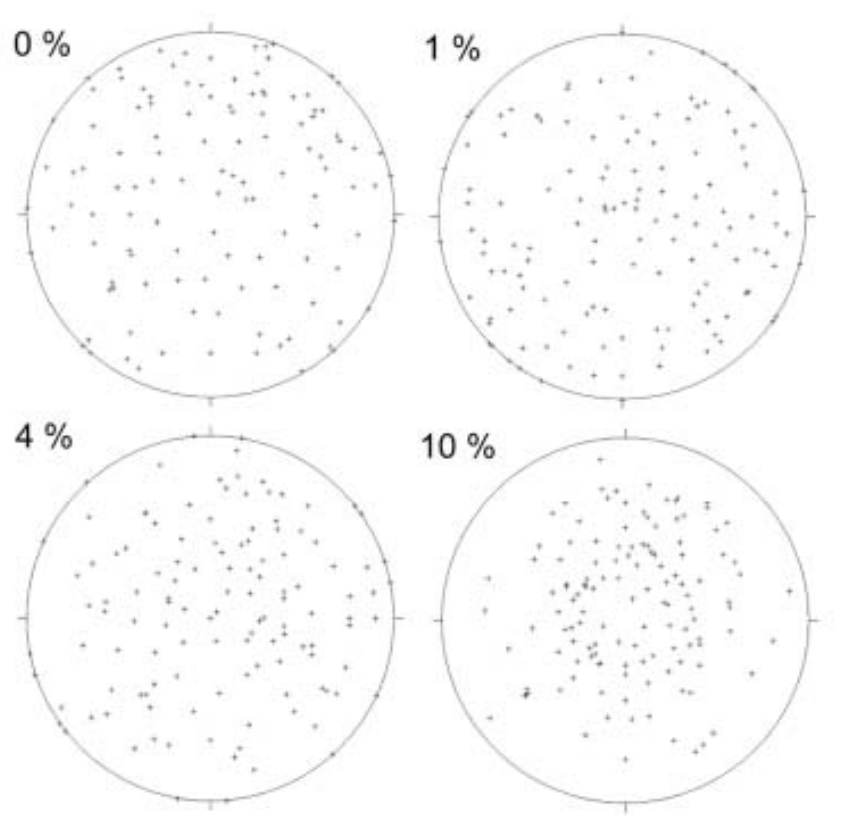

Fig. 8. Orientations of the $c$ axes for particle-free ice at the indicated creep strain level, $T=-10^{\circ} \mathrm{C}$.

dramatically and the $c$ axes of the fine grains show a tight single-pole fabric. In our laboratory results on particlecontaining ice, grain-size decreases dramatically compared with fresh-water ice during creep. However, since our ice with particles did not have enough time and deformation to develop the strong fabric that was evident in the dust-band ice cores (Gow and Williamson, 1971), the difference in fabric development is not surprising.

\section{CONCLUSIONS}

The effect of particles on the creep, dynamic recrystallization and fabric development in granular fresh-water ice has

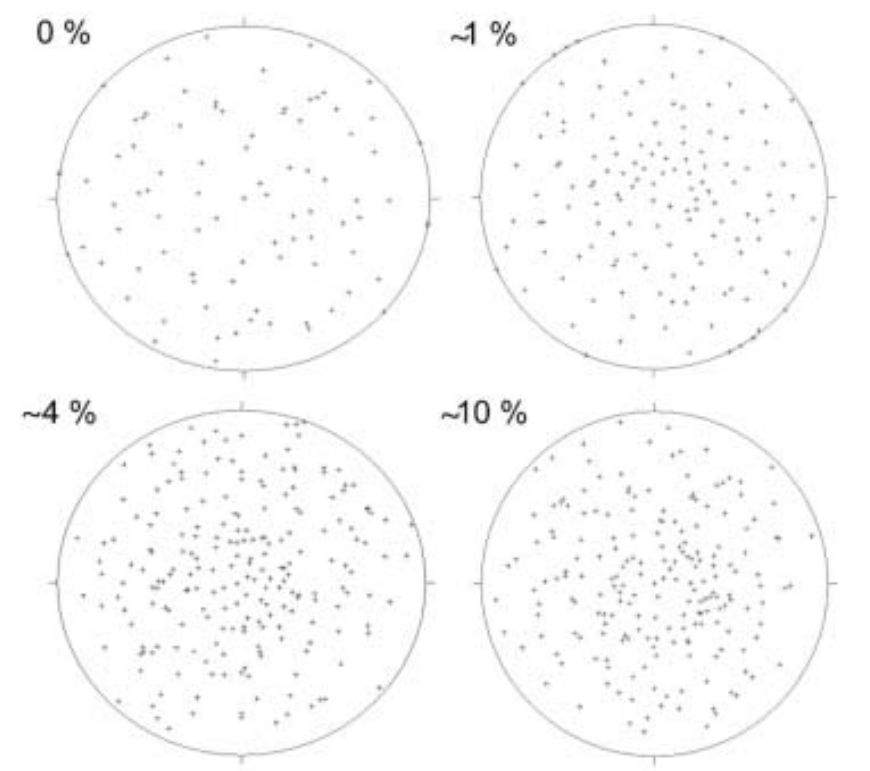

Fig. 9. Orientations of the $c$ axes for ice with $1 \mathrm{wt} . \%$ particles at the indicated creep strain level, $T=-10^{\circ} \mathrm{C}$. 
been investigated and the following conclusions are drawn:

Ice with 1 wt.\% particles shows a higher creep rate at all stages of creep than particle-free ice.

New, small, grains nucleate along the grain boundaries for both the particle-free ice and particle-laden ice.

Particles inhibit grain boundary sliding and enhance dynamic recrystallization through the development of high local strain energies, leading to particle-stimulated nucleation and dramatically decreasing the grain-size.

The fabric for particle-free ice shows a weak girdle shape. Particles inhibit the development of this fabric by nucleating grains with nearly random orientations.

\section{ACKNOWLEDGEMENTS}

This research was supported by the US National Science Foundation Office of Polar Programs, Arctic Natural Sciences Program (OPP 011737). We thank G. Durell for his valuable assistance in developing the creep loading equipment and E. Andreas for her valuable help with the orientation measurements.

\section{REFERENCES}

Azuma, N. and A. Higashi. 1985. Formation processes of ice fabric pattern in ice sheets. Ann. Glaciol., 6, 130-134.

Baker, I., F. Liu, K. Jia, X. Hu, D. Cullen and M. Dudley. 2000. Dynamic observations of dislocation/grain-boundary interactions in ice. Ann. Glaciol., 31, 236-240.

Baker, R.W. and W.W. Gerberich. 1979. The effect of crystal size and dispersed-solid inclusions on the activation energy for creep of ice. J. Glaciol., 24(90), 179-194.

Bleck, W. and H.J. Bunge. 1981. The recrystallization of AIMn 1 investigated with pole figures by number. Acta Met., 29(8), 1401-1412.

Cole, D.M. 1979. Preparation of polycrystalline ice specimens for laboratory experiments. Cold Reg. Sci. Technol., 1(2), 153-159.

Cole, D.M. 1993. The effect of creep on the constitutive behavior of saline ice at low temperature. In Dempsey, J.P., Z.P. Baz̃ant, Y.D.S. Rajapakse and S.S. Sunder, eds. Ice mechanics 1993. New York, American Society of Mechanical Engineers. Applied Mechanics Division, 261-271.

Cole, D.M. 1995. A model for the anelastic straining of saline ice subjected to cyclic loading. Philos. Mag. A, 72(1), 231-248.

Cole, D.M. and G.D. Durell. 1995. The cyclic loading of saline ice. Philos. Mag. A, 72(1), 209-229.

Cole, D.M. and G.D. Durell. 2001. A dislocation-based analysis of strain history effects in ice. Philos. Mag. A, 81(7), 1849-1872.

Cuffey, K.M., H. Conway, A. Gades, B. Hallet, C.F. Raymond and S. Whitlow. 2000a. Deformation properties of subfreezing glacier ice: role of crystal size, chemical impurities, and rock particles inferred from in situ measurements. J. Geophys. Res., 105(B12), 27,895-27,915.

Cuffey, K.M., T. Thorsteinsson and E.D. Waddington. 2000b. A renewed argument for crystal size control of ice sheet strain rates. J. Geophys. Res., 105(B12), 27,889-27,894.

Durham, W.B., S.H. Kirby and L.A. Stern. 1992. Effects of dispersed particulates on the rheology of water ice at planetary conditions. J. Geophys. Res., 97(E12), 20,883-20,897.
Duval, P. 1981. Creep and fabrics of polycrystalline ice under shear and compression. J. Glaciol., 27(95), 129-140.

Duval, P., M.F. Ashby and I. Anderman. 1983. Rate-controlling processes in the creep of polycrystalline ice. J. Phys. Chem., 87(21), 4066-4074.

Goldsby, D.L. and D.L. Kohlstedt. 1997. Grain boundary sliding in fine-grained ice I. Scripta Mater., 37(9), 1399-1406.

Gottstein, G. and L.S. Shvindlerman. 1999. Grain boundary migration in metals: thermodynamics, kinetics, applications. Boca Raton, FL, CRC Press.

Gow, A.J. and T. Williamson. 1971. Volcanic ash in the Antarctic ice sheet and its possible climatic implications. Earth Planet. Sci. Lett., 13(1), 210-218.

Gow, A.J. and T. Williamson. 1976. Rheological implications of the internal structure and crystal fabrics of the West Antarctic ice sheet as revealed by deep core drilling at Byrd Station. Geol. Soc. Am. Bull., 87(12), 1665-1677.

Habiby, F. and F.J. Humphreys. 1999. The effect of particle stimulated nucleation on the recrystallization texture of an AlSi alloy. Scr. Metall. Mater., 30(6), 787-790.

Holdsworth, G. and C. Bull. 1970. The flow of cold ice: investigations on Meserve Glacier, Antarctic. International Association of Scientific Hydrology Publication 86 (Symposium at Hanover 1968 - Antarctic Glaciological Exploration (ISAGE), 204-216.

Huang, Y. and F.J. Humphreys. 1999. Measurements of grain boundary mobility during recrystallization of a single-phase aluminium alloy. Acta Mater., 47(7), 2259-2268.

Humphreys, F.J. 1980. Nucleation of recrystallisation in metals and alloys with large particles. In Hansen, N., A.R. Jones and T. Leffers, eds. Recrystallization and grain growth of multi-phase and particle containing materials. Roskilde, Denmark, Risø National Laboratory.

Humphreys, F.J. and M. Hatherly. 1996. Recrystallization and related annealing phenomena. Oxford, etc., Pergamon Press.

Jacka, T.H. 1984a. Laboratory studies on relationships between ice crystal size and flow rate. Cold Reg. Sci. Technol., 10(1), 31-42.

Jacka, T.H. 1984b. The time and strain required for development of minimum strain rates in ice. Cold Reg. Sci. Technol., 8(3), 261-268.

Jacka, T.H. and M. Maccagnan. 1984. Ice crystallographic and strain rate changes with strain in compression and extension. Cold Reg. Sci. Technol., 8(3), 269-286.

Lange, M.A. and T.J. Ahrens. 1983. The dynamic tensile strength of ice and ice-silicate mixtures. J. Geophys. Res., 88(B2), 1197-1208.

Langway, C.C., Jr. 1958. Ice fabrics and the universal stage. SIPRE Tech. Rep. 62.

Nayar, H.S., F.V. Lenel and G.S. Ansell. 1971. Creep of dispersions of ultrafine amorphous silica. J. Appl. Phys, 42(10), 3786-3789.

Shoji, H. and C.C. Langway, Jr. 1985. Comparison of mechanical test on the Dye-3, Greenland ice core and artificial laboratory ice. Ann. Glaciol., 6, 306-308.

Somerday, M. and F.J. Humphreys. 2003. Recrystallisation behaviour of supersaturated Al-Mn alloys - Part 1. Mater. Sci. Technol., 19(1), 20-29.

Song, M., D.M. Cole and I. Baker. 2004. Initial experiments on the effects of particles at grain boundaries on the anelasticity and creep behavior of granular ice. Ann. Glaciol., 39, 397-401.

Van der Veen, C.J. and I.M. Whillans. 1994. Development of fabric in ice. Cold Reg. Sci. Technol., 22(2), 171-195.

Wilson, C.J.L. and H.M. Sim. 2002. The localization of strain and caxis evolution in anisotropic ice. J. Glaciol., 48(163), 601-610. 